\section{dintrodurctory gooress}

\author{
DELIVERTD AT THE OPENING OF
}

\section{ST. MARY'S HOSPITAL MEDICAL SCHOOL,} OCtober 2ND, 1865.

BY

C. HANDFIELD JONES, M,B., F.R.S., PHYSIÇAN TO THE hosPLTAI.

Gentramen,-The time-honoured custom of prefacing the commencement of each session of medical study by an address, delivered by one of the teachers of each achool, has much, I think, to commend it to our approval; and one of its advantages may be this - that it affords us an opportunity of reviewing our position, and setting before our minds the chief features of the changing scene. It seems to be a natural tendency implanted in us all to portion out the time given to us, and to pause at the end of various periods, and consider more or less closely what our progress has been, and what our prospects appear. The wise man, deeply conscious of the value of time, will be ever desiraus thus to panse and consider his ways; and even the most heedless and unthinking can hardly avoid some reflection as the stream of time, which is bearing him on, turns, and opens before him, as it were, another of its long reaches.

Wisely is it ordered, no doubt, that the yearreturning iviauros, our natal day, and the commencement of set pexiods of labour, should thus invite us to salutary thourghts; which may beoome the spring of renewed and improved action. "It falls to my lot toiday to be the one who is deputed by the staff of St. Mary's to greet again the friends : and older studenta of the hospital and school, and to held ont the right hand of welcome to the younger, who come to us now for the first time. To each and all of these, and through them, perhaps, to otlers apound us, I must strive to say: a few words. And when I think that, humanly speaking, it is extremely: improbable that I shall ever have the like opportunity again, I oannot but feel anxious that I may be able to say semething which shall have a voice to the heart.

Looking to the general condition of the profession which some of you are about to join, while there are not a few things that one would wish otherwise, I think, on the whole, that we have much: ground of legitimate satisfaction and encouragement. It cannot be denied that, taking as all in all; we are doing all over the land-I may say almost all over the world-a vast deal of downright, real, honest, and beneficial work, which, if not always appreciated or rewarded as it deserves, yet often is so; and which not unfrequently becomes the cause of our being linked in pleasant and friendly relations with those whom we cannot but esteem and love. To do good work, and to be loved for doing it, is surely a lot which many a man might envy, and with which we may be well content. If the prizes which are to be won in the legal, clerical, and military professions, are not open to us, this is not to my mind any source of very deep regret. It is better, as an old saying has it, to deserve and not to have, than to have and not to deserve. How many of those who do gain thase distinctions can be said fairly ta have earned them? In how many instances are they not simply the gifts of fortune, or procured by interest? The medical practitioner need not thirst to make his way into the aristacracy of titie place, power, and wealth; he belongs, or his aim should be to belong, to a higher grade-the aristacracy of intellect. His ambition should be to gain suoh a power and mastery in dealing with disease, that he may be looked up to by his fellow-mortals as a superior being, to whom, in some measure, the Creatar has entrusted the power of restoring health and preserving life. . As such, and in so far as he is worthy the name of healer, he hotds a position inferior in real dignity to none except that of him who ministers in holy things. He maty surely afford to look very calmly on the external trappings of inherited nobility, or those of the rank which is procured by interest or wealth. He will hardly, methinks, care to exchange places with the conqueror or with the statesman, when he remembers that his triumphs bring no misery like those of the former; and that, unlike the latter, he has to deal with the steadfast laws of Nature, rather than with the passions and prejudices of men. We may, I think, be well satisfied with our place in this passing scene, as one in which we have no mean opportunity of serving. God and benefiting our fellows; and, instead of aiming after that which would be hardly more than outside glitter, let us strive after real power-the power which comes of industry and energy in our appointed work. I would that, as a profession, we were more zealous and anxious for this-that our power to heal might be increased. I would, not that there was less of individual effort, but much more of combined, to win from Nature the secrets of healing and prevention of disease. We have already choiee first-fruits ; but there must surely be many more waiting the diligent seeker; and I cannot but wish that this search were pursued on a larger scale, and with adequate means.

Believing thus that our social position depends very much on our own intrinsic worth, I do not think that we must look for much advantage from any legislative interferemce in our behalf. No Medical Act will ever suppress quseks, any more than it will eradicate the love of quackery which is so innate a tendency in many minds. Even aross the Channel, where the liberty of the subject is much less tenderly dealt with than among ourselves; quackery, ag. M. Dumont tells us, is rampant enough, in spite of probikitions and fines. Omne ignotum will always be held pro magnifica by the lovers of the marvellous; and an unscrupulous and ignorant boaster, who can lie through a deal board, will always, with certain minds, have : an advantage over the man whose knowledge of disease pnevents him from being blind to threatening dangers, and whose conscience will not suffer his tongue to utter that which he knows to be untrue. These are vexations which we shall always have to contend with; and I doubt very much whether they will ever be removed, even by the increased diffusion of sound scientific kncwledge. A medical friend once related to me the instance of a man of considerable scientific attainments, thoroughly versed in electrical matters, who suffered from some obscure neuralgic or rheumatic pains, for the relief of which he wore one of the so-called galvanic rings which were in vogue some years ago. His reason told him that it was utterly impossible that any galvanic current could be gererated by this ring, but nevertheless he wore it; and, when rallied by my friend on his credulity, he admitted the absurdity of the notion, but added, "I believe, nevertheless, the thing has some virtue." And a virtue it had, no doubt; but this proceeded, not from any. 
thing existing in itself, but from the mental state it induced in the wearer. He had a faith in his ring; and this faith overruled his reason, and gave a power to the ring which it could never have had without. I may refer to this subject again; but, before I pass on from my notice of quackery, I wish to make some remarks upon one form of it, in order to set ourselves right on one point in which I think we are often misrepresented.

The advocates of what is called homøopathy put forth that our repudiation of their views relates to their dogma about those remedies having a curative virtue in certain morbid states, which, when administered in the healthy condition of the system, produce these same morbid states; or, as it is shortly expressed, that "like cures like". This dogma would lead us, if we accepted it, to give urate of soda for the cure of gout, or an extract of the stools of typhoid patients for the cure of others labouring under the same fever. It certainly does not sound promising to an inquirer after rational science; but yet I will venture to say this is not the main cause of our refusing to have anything to do with homøopathy and its professors. A man might, I conceive, hold any view as to the modus operandi of remedies, and yet be one with whom I could consistently advise and act. But when a man takes up, as a fundamental part of his therapeutics, the notion that the more a substance is attenuated, the stronger are its effects-when he renounces the administration of drugs in doses which produce a perceptible action. and puts his faith in infinitesimal quantities of common salt, silica, and the like-one can only say that his mind and mine have no common ground of action in the cure of disease; and that it is, therefore, simply impossible we can cooperate. You might as well ask two engineers to consult together about erecting a bridge, one of whom believed that the weaker the supporting structures were made, the greater would be their power of enduring strain. I believe that the absurdity of this dogma of infinitesimal doses is felt pretty kes aly by some of this tribe, and they would fain make out that it is no essential part of what they call their system. It stands, however, written indelibly in their text-books, and is so essential a part of their system that, if it were re. moved, the public would utterly fail to distinguish between them and us. Some of the laity, I know, have an idea that the peculiarity of homoopathic medicines is, that they contain only the potent essences and active principles of ordinary drugs, extracted from the coarser preparations by recondite processes; and that they are, therefore, comparable to our aconitine or atropine. 'This notion is, of course, utterly without foundation; and the public should know that it is so. When the case of homoopathy is stated thus, on the real grounds by reason of which we, as rational practitioners, refuse to have anything to do with it, I think none, however biased they may be in favour of this phase of quackery, can possibly charge us with being indifferent to the discovery of truth, or bigoted adherents to an old belief. Who, I would ask, are more ready to adopt and test every new proposal for the cure of disease, than medical practitioners? and who are more ready to proclaim the virtues of any means that approves itself on fair investigation? Were not iodide of potassium, chloroform, and cod-liver oil received, I might almost say with open arms, by the profession? Did we not, in public and private practice, fairly test the worth of Dr. Fell's claims for the cure of cancer? And have we not carefully endeavoured to estimate the value of hypophosphites and other remedies, not excluding even snakes' dung, in the treatment of phthisis? A clergyman once said to me that he thought no class of men were more truly doing Christ's work on earth than the medical profession, on account of the ready, hearty way in which they had promoted sanitary improvements, to their own manifest disadvantage. Could we receive homœopathy without abandoning our common sense, and, I might almost say, our common honesty, the case would be very different; but, so long as such old-fashioned qualities stay by us, we are bound to keep ourselves clear of all dealings with it, and must rank its instances of apparent success either as the results of good hygiene or of implicit faith, or, as Dr. Roberts has given us ample proof, of the clandestine administration of non-homœopathic medicines. But enough of this matter.

The allusion I have just made to the influence of faith leads me to ask you to consider this matter with me somewhat in detail. It seems to me worth while to endeavour to have some distinct information on this head, and that we ought not to rest content with vague notions about the power of imagination and the effects of psychical agencies on the body. Unless we are fully satisfied in our own minds that these are verce causce, and to what extent they are so, we have of course no right to ascribe to them the results obtained by quacks, which sometimes appear striking enough.

For the sake of illustration, I will cite briefly some authentic histories from the annals of our army and navy, which prove unquestionably that different states of the mind and feelings act powerfully either in promoting the operation of morbid impressions and miasms, or in enabling the frame to resist them. Dr. James Johnson relates that H.M.S. Russell, 74, sailed from Madras Oct. 22nd, 1806, and arrived at Bataria Nov. 27th, the crew healthy, and their minds highly elated with the sanguine expectations of surprising the Dutch squadron there. Such, however, was their sudden disappointment and concomitant mental depression on missing the object of their hopes, that they began immediately to fall ill, ten, twelve, or fourteen per day, till nearly two hundred men were laid up with scurvy, scorbutic fluxes, and hepatic complaints. Of these upwards of thirty died before they got back to Bombay, and more than fifty were sent to the hospital there. The Albion did not fare better. The Powerful fared worse. So that in these three ships alone, in the short space of a few months full one hundred men died on board, and double that number were sent to hospitals, many of whom fell victims to the above-mentioned diseases, which had been aggravated, and in a great measure engendered by mental despondency. When we remember that the sufferers in this instance were not delicate and sensitive persons, but hardy sailors, we must admit that the record strongly sets forth the influence of mental depression; while the two following incidents exhibit the opposite result of cheerful excitement. During the week in which Hill's division surprised that of Gerard at Aroyo de Molinos in Spain, during the Peninsular war, the rain was heavy and almost incessant, and the men passed two nights in bivouac without fires, yet fewer of these men fell sick during that and the subsequent week than in any equal period during the year. Dr. Luscombe assigns as the reason of the immunity of the soldiers from the effects of fatigue and exposure to cold and wet, that they were under exercise and mental excitement. During the epidemic yellow fever of 1822 in Jamaica among the soldiers of the 91st Regiment, when the order was issued for their removal to another station, the fever ceased; and, though the corps was unexpectedly detained for three or four days after the order was issued, not one case was admitted into hospital during the whole of that 
period. I have quoted these instances from Sir Ranald Martin's classical work, because it can seldom happen in civil life that events on so large a scale come under the observation of any of us, and what we do not see strikingly exhibited we are to pass unnoticed, according to the old dictum, "De non apparentibus et non existentibus eadem est ratio."

I proceed now to my more immediate object, which is to illustrate by examples how mental influence modifies the action of medicines, or at least intervenes in such a way that its concurrence or resistance has to be taken into most serious account in estimating the effects produced. An elderly medical man, of unquestionable veracity, told me that, when a young man, he had a gentleman under his care, rather advanced in years, who consulted him for a sore on his leg. This sore was quite of an asthenic character-very probably a varicose ulcer; at any rate, mercury was quite contra-indicated. The patient, however, fancied it was of syphilitic origin, and wanted to have mercury given him. My informant refused for a long time, and his recusance was backed by the opinion of an hospital surgeon, who was called in consultation. They continued to treat the case together for some time with various remedies; but, at last, finding they made no progress, and the patient retained the same fixed idea of the necessity of mercury, they agreed to employ a ruse. They said they were now satisfied that he was right, and that mercury must be given, but it must be with great caution; and one of their directions was, that an attendant should sit up with him every night to watch the first appearance of the gums becoming affected. 'The object of this was of course to rivet more strongly on the patient's mind the notion that he was taking the desired remedy. No mercury was really given; but from this time the sore began to improve, and soon got well. Dr. Horace Green related the following story to Dr. Simpson of Edinburgh. A lady had been useless and bed-ridden for years; the spine was her own alleged seat of disease; and endless measures had been tried to restore her to health, and the power of standing and walking; but they had all been tried in vain. In consequence of the earnest advice and glowing representations of some female homoopathic friends, she had been long anxious to ascertain if homœopathic tre ttment could be of any use in her distressing case ; but her husband refused to give his consent, believing homœopathy to be a discreditable delusion and quackery. Fortunately, however, for herself, her husband left her for a week or two on a sporting expedition; and as soon as he set off with his gun and dogs, she seized hold of the opportunity which she had long desired of consulting a celebrated homoopathic physician. The physician listened long; examined into her case most attentively; made before her written entries and memoranda regarding all her symptoms and sufferings; and at last, on considering the whole, confidently assured her, that doubtless he could send her a drug that corresponded with her disease, and which would produce such effects the first day, other effects the next, etc., and that before her husband returned she would be able to walk and enjoy life. The patient diligently swallowed certain globules; all the predicted effects duly followed; and, when her husband returned home, he was astonished and overjoyed to find his sick and bed-ridden wife up and well. The crime of consulting an homøopathist against his declared wish was readily forgiven, seeing the results of the treatment had been so happy and beneficial; but he asked for a sight of the wonder-working globules which had produced so gladsome a change in his wife's health, and in his own prospects of domestic happiness. On boing shown the globules, the acute and loving husband earnestly desired them to be most carefully preserved and locked up, lest perchance his partner's distressing ailments should at any future time return. He then went and informed his usual family physician of this secret, that his wife had got well under an homœopathist; adding, that still he did not believe in homœopathy itself, for he found that the globules which she had swallowed were not hounoopathic drugs, but specimens of some small percussion pellets to be used instead of caps for his gun, but which had not arrived at the house until some time after he had left. The servant had mistaken the packet of pellets for the packet of homoopathic globules; and the lady had swallowed them under the belief that she was swallowing the homœopathic physician's medicine. A writer in the British Medical Review for 1847 relates three cases in which intractable maladies, which had resisted various remedies, gastralgia, enteralgia of organic origin, and protracted constipation, yielded to breadpills. In the last instance, four successive previous attacks had each required the administration of the strongest purgatives (croton oil included), powerful enemata, cold affusions, and hot baths, before relief was obtained. On the fifth attack, he was put under two grains of bread-pill every seven minutes, much anxiety being of course expressed to guard against an over-dose, as well as to watch the effect of what was thus given. Within two hours, he became sick (one of the symptoms expected from the medicine), and his bowels were freely open almost immediately after. Dr. Simpson says that he has known simple bread-pills act as aperients, as diaphoretics, as diuretics, as narcotics, etc., when the patients swallowed them under the mental impression and conviction that they were drugs calculated to produce these special effects. In one case, salivation and spongy guins followed the use of bread-pills-the patient believing that his medical attendant was exhibiting to him, what he had experienced before, an active course of mercury. Dr. Routh relates how a strong, wellbuilt man, about 25 years old, labouring under some dyspeptic affection, was attacked with syncope and convulsive movements, after each dose of thirty drops of water coloured with compound lavender tincture, while he remained free when the dose was reduced to twenty drops.

Such facts as those now cited are familiar enough to the more learned and experienced of our profession; but are too often far from being sufficiently considered. I should almost apologise for mentioning them, did I not consider it of great importance for the student who has made some advance in his professional training, and may be about to enter on practice, to have a clear comprehension of the influence which mental states may, and assuredly will in some instances, exert on the material frame both in the causation and in the removal of disease. If he have not this knowledge, he is very liable to be sorely annoyed and discomfited by the apparent success of impudent and dishonest charlatans, which better information would have shown him was reasonably to be accounted for by other causes than the efficacy of the physical agents employed. True it is, he may suffer loss in pocket by such events; but his spirit will not be bowed with any fear of being in a false position, or with the idea that he has to abandon his sound common sense and take up with monstrous absurdities, which require abnegation of all accurate thought, and are only worthy of dreamy mystics. A true and honest mind can be content to toil on, bearing the rubs and disappointments of life, so long as he is well assured that his foot stands firm in the way of real truth; but it would indeed paralyse his energy, if he suspected that he was deluding himself 
and others; that his pretensions to relieve suffering and cure disease were all fallacious; and that he had travelled so far entirely on a wrong road. Some weak minds desirous of doing right, but unacquainted with the power of medical faith, and with the vis medicatrix naturce, may have been perverted into the ranks of quackery under the expectation of acquiring in their new position marvellous powers of healing-a hope which, I need not say, is destined to utter disappointment. It is to shield any of my junior hearers from such possible perversion that I have thought it worth while to state thus prominently the over-mastering influence of certain states of mind, acting, no doubt, through the nerrous system.

I have just referred to the natural tendency which the system possesses to return to a state of health after it has suffered from some cause of derangement; and I wish not to pass this subject by without some remarks, as it is one which justly has been much insisted upon of late. It may be taken as a point which is now generally admitted, that many acute diseases have, when left to themselves, more or less tendency to terminate in restoration to health. I say adrisedly more or less; for it seems to me unquestionable that this tendency varies greatly in degree in different individuals, at different periods, and in different morbid affections. In some it is evident and constant enough, and no one doubts about it; in the majority, it is much more feebly marked, and often is scarcely discernible. 'Thus, it is known to every one that the exanthemata and continued fevers have a tolerably definite duration; rheumatic fever and malarious have a much less determinate; and the same holds good of the ordinary inflammations of different viscera and organs. In many of these, it is difficult to distinguish accurately between the original morbid action and its results; the effects of secondary disease are so mixed up with those of primary, that it is impossible to determine when the latter terminated. Further, the duration of diseases of the same kind depends in some considerable measure on their gravity; i.e., on the degree in which the system is affected by the morbid influence. The frame which is gravely stricken suffers much longer, remains for a much longer time in an abnormal condition than the one which is visited more gently. Here, also, we must notice the modifying agency of constitution and diathesis. The strong system, whose organs are, as it were, confirmed and rooted in habits of healthy action, is with difficulty thrown into disorder; and, when its working is for a time deranged, its parts soon resume their wonted healthy play. With the weak system it is very different; it has no elastic resiliency towards health; and when it has once deviated from the normal mode of working, it is very apt to remain in the same condition a long time. I use the epithet "weak" in a very general sense, to imply all sorts of impairment or deterioration of the healthy mode of life. One system may deviate in one direction and another in another, according to their peculiar tendencies. Taking diseases as we find them actually existing, it seems to me that, with the exception of a few (just enough to make the contrast of the others more marked), we have very little indication of the existence of any determinate periods limiting the natural duration of the disorder. With a multitude of chronic diseases, this is unquestionably the case, and between them and the acute there exists no absolute line of demarcation; they pass into each other by various grades of subacuteness. Holding, then, this belief that disease is an extremely varying and inconstant thing; which utterly refuses to adjust itself to strict definitions, or to be bound by a settled reckoning of days and hours, I cannot think that the proposal which has found much favour in the eyes of some of our best physicians - to ascertain the natural history of all diseases, as an indispensable preliminary to forming any opinion as to the effect of remedies-is likely to lead to any result. The fundamental idea of the proposal is, that the several pathological states to be examined can be regarded as uniform and constant, each case of each kind being truly similar to those which are ranked with it. Were this so, at least to any considerable extent, the problem would be conceivably soluble; but, as the case actually exists, the idea seems to me impracticable. For, if one thing is impressed upon me more than another by increasing experience, it is the great diversity which exists between the several morbid states, which "stant unius sub nominis umbrâ", and which have an outside show of similarity in their location and symptoms. A case of erysipelas occurring in an inhabitant of a large town, with a system long deteriorated by foul air, bad beer, worse gin, and other like influences, is not like a case occurring in a robust, well-fed farmer. The external appearance of the inflammation in the two cases may be very similar; but the state of the vital powers which determine the tendency and issue of the pathological processes is very different. The same holds good, I believe, of pneumonia, pleurisy, croup, pericarditis, dysentery, and almost every disease which can be named. Skoda seems now, as the general result of his experience during six years, to be satisfied that pneumonia may be a very different disease quoad its mortality in one period from what it is in another, quite irrespective of the kind of treatment, and though no reason for the change can be discovered. The reporter of the Vienna Hospital for 1860-61-62, in commenting upon pneumonia, makes the following judicious remarks : "Individual cases of pneumonia are often so dissimilar, that it is impossible to put them all into one class, and to lay down for their treatment one and the same method. The aspect of the patient, the state of the pulse, of the nervous and muscular systems, and of the skin, the sputa, etc., must reveal to us the true quality of the disease." Hjaltelin, writing respecting an epidemic of pneumonia in Iceland, states that it very often happened that healthy strong persons were so rapidly affected that death ensued in two or three days, and that this was the general rule when the disease was left to itself. In several parishes where no medical aid could be obtained, nearly all those who were attacked died. Such pneumonias must have been of different quality to those recorded in Dr. Balfour's report of cases treated in Fleisc!mmann's Homœopathic Hospital at Vienna, where the mortality was only three in nineteen; or those treated by Skoda, in the same city, with extractum graminis, among whom the deaths were only three in forty-five. Scarlatina, we know, may be of such a nature that it constitutes, as Sydenham said, scarcely the shadow of a disease; and, on the other hand, may be as deadly and virulent a malady as any that has ever scourged the earth. Looking at all these things, I cannot but fully endorse $\mathrm{Hjal}$ telin's statement, that diseases are certainly no stable things, no individuals; but very variable pathological phenomena, modified in an indefinite manner according to various causes which produce them. Dr. Sieveking has some valuable remarks nearly to the same effect. He says: "The wise physician does not regard the disease as a nosological abstraction, but as a deviation from the healthy standard involving a great variety of elements, each of which may in its turn differ in degree, character, and relation, in any given number of patients brought together for comparison." Now, if the groups of morbid processes 
which we call diseases are made up of such varying and unstable materials, how can we hope to ascertain the periods during which they will continue when left to themselves? Must not these be as varying as their elements are?

I fear that, in expressing these opinions, I may seem to some, for whose judgment $I$ have great respect, to be opposing the efforts of those who are striving to approximate medicine to the condition of an exact science. No one would rejoice more than $I$, if the almost proverbial uncertainty of medicine could be replaced by clear foresight of, and greater control over, the events of disease ; but I fear lest, in striving after the unattainable, we should lose sight of the true course to be pursued. I believe it is impossible that medicine can ever be an exact science, such as astronomy, mechanics and chemistry are, because the phenomena which their students have to investigate are of a much more constant and definite kind, and more accessible to observation, than the morbid processes which go on in living bodies. Attraction, mechanical force, and chemical affinity always act in the same way-always produce the same effects; but the causes of disease do not. Their results are, to a very great extent, regulated by the receptivity of the frames on which they act. One system reacts in one way, another in another, and a third is unimpressed at all. For these and for various other reasons, medicine must, I think, ever come very short of the exactness which other sciences can claim. Yet there is no doubt to my mind that it is a true science, if by that term we understand a collection of facts acquired by careful observation, and framed into laws of more or less wide extent by the process of induction.

If it should seem to any student that the view I have just given of the variableness and inconstancy of disease makes the acquisition of practical knowledge appear a matter of exceeding difficulty, let me assure him that this, like many other difficulties, looks much more formidable than we find it is when we grapple with it. It needs but a moderate amount of professional training and of sound sense to enable any one to treat most diseases pretty correctly. If we lay aside all routine-prescribing for the name of a disease, and consider each case according to the indications for treatment which it presents, we shall never be far wrong.

And now, having touched on various points which have more or less interest for us all, whether we be grey-haired and advanced students, or juniors yet in statu pupillari, I turn to address a few words especially to the latter.

I pray you, gentlemen, to believe me entirely, when I say that, in common with all my colleagues, I take a real and lively interest in your welfare; and that the counsel I offer you comes from a warm and sincere heart. Standing as I do on the commencement of the downward slope of human life, I may claim to speak to you with some of the authority given by experience, while at the same time I feel that age has not so quenched the fire of my blood that I am unable to participate with you in your zest for physical enjoyments. I want you to believe that I speak to you as no formal, cold, and exacting monitor, who looks on what he calls the follies of youth with contempt, and thinks nothing so important as red-tape and rules and guineas. I rejoice and sympathise heartily with the exulting spirits of youth, and think there are few gifts more precious than its cheerful hope and its active energy. But, just because they are so precious and fleeting, does it seem to me of the utmost consequence that they should not be wasted, but made to minister to worthy objects, and to produce good and lasting fruit. Be- sides this, it would be vain to shut one's eyes to the fact that youth is, by its constitution, peculiarly exposed to the temptations of carelessness and neglect of duty; and that especially in this vast city, where it is no easy matter to obtain healthful recreation, there is much risk that the devil's substitutes should be admitted by the unwary.

I wish, then, to try and set before you, in plain language, the principles and views which seem to me to form the best guides for a student who is now engaging or engaged in a course of medical study.

First, I assume, as surely it is not too much to do in a Christian land, that he believes that glorious old book, the Bible, in its plain, natural sense, and is not ashamed to look his fellows in the face and say, "I mean that book to be my rule of life." Thank God, the time is pretty well gone by when religion was looked down upon with contempt, and when profane oaths and loose talk were considered indications of a manly spirit. The world is pretty well satisfied now that the heartily God-fearing man may be one of the most eminent in any walk of life, and is inclined to respect him accordingly. "Call out the saints," cried Lord Gough, when some difficult emergency occurred ; " Havelock never blunders, and his men are never drunk." The student who will read his Bible as Havelock read his, will find it make him in his sphere what Havelock was in hisone of God's own heroes. He will find its instructions will make him a wiser and better, a holier and happier man. It bids him hallow his Sabbaths; and no one, I believe, has ever done this without finding that it has a most beneficial influence on mind and body, over and above its direct intention and tendency to endue us with preparedness for the coming eternity. In these days, when we so often meet with indications of failing nerve-power, I know no more necessary preservative to commend to the student who would preserve vigorous energy of mind and body, than the regular observance of Sabbath rest from secular business, as far as the calls of duty permit. The Bible frowns upon nothing but what is bad and base, and godless and unmanly; it commends to us whatsoever things are honest, just, pure, lovely, and of good report. Its intention is to bring back our alienated nature to God, and thereby to raise and ennoble it. All experience tells us how utterly degraded man becomes in proportion as he recedes from God and ceases to experience his influences. On the other hand, everything that draws us to God has the contrary effect. Hear what Bacon says. "Take an example of a dog, and mark what a generosity and courage he will put on when he finds himself maintained by a man, who is to him instead of a god, or melior natura; which courage is manifestly such as that creature, without that confidence of a better nature than his own, could never attain. So man, wher he resteth and assureth himself upon Divine protection and favour, gathereth a force and a faith which human nature in itself could not obtain. Therefore, as atheism is in all respects hateful, so it is especially in this, that it destroys magnanimity, and depriveth human nature of the means to exalt itself above human frailty." This passage would lose to us much of its force and significance, if I did not add Julius C. Hare's comment upon it. He says : "Practically, every man is an atheist who lives without God in the world." To this practical atheism we are all far too prone. But I ask you to believe the testimony of some of the wisest and best of our race-that it is good for us to draw near to God; and to lay this thought to your minds-that in doing your daily work to Him, and regulating your lives by the desire to please Him, you are most truly ennobling your own nature, and preparing for your- 
selves the purest sources of present and future happiness. Such conduct, be assured, is truly manly.

Next coming to speak of your studies, I feel myself rather at a disadvantage, because you are unable to pursue them in the way which I strongly believe to be the best. Of all crafts, none more than medicine absolutely requires that the learner should familiarise himself with things, with actualities, more than with words. You may read books and hear lectures to any amount, and yet be extremely unfit to treat a case of ordinary disease, perhaps even unable to recognise it. Of course, you must read; but, unless you see, and hear, and handle, and smell, the things and beings about which you read, your study will avail you little. Reading has this most essential advantage over listening to a lecture, that every passage can be well and quietly considered, while a lecturer must necessarily often pass on far more rapidly than many of his audience can follow. Do not think that I depreciate lectures; in their proper place, I think them most valuable; but the day when systematic knowledge could be advantageously imparted by these means has, I am convinced, passed away. For clinical teaouing, they must ever remain the appropriate means; and to this I would limit them. In the present day, we have so many excellent standard works which contain really all that the student can possibly carry, that I do not see how we benefit him by compelling him to hear and read the same matter. And as for the illustrations, which are said very justly to be an important part of a good lecture, the student should have them brought before him in museums, dissecting-rooms, hospital-wards and out-patientrooms, and post mortem examinations. I can quite understand that the indolent man finds it easier to sit and yawn on the benches of the theatre while the bones are being demonstrated, than to take a set in hand himself, and con them well over with Ward or Holden or Gray, till he has mastered their intricacies. But what sort of knowledge, let me ask, does the mere listener get, and how long does it stay by him? So with all the other subjects, except perhaps chemistry, where demonstrations of the properties and qualities of bodies can be made with evident advantage and economy to a class. Even here, however, personal work in the laboratory is indispensable to the man who wishes to attain any real knowledge of chemistry. What our examining boards should require is, simply that a student should show that he his attained a competent knowledge of the things he is required to learn; and they should leave it very much to the student himself to acquire this knowledge in the best way he can. What our schools should do, I conceive, is to provide the student with all means, aids, and appliances, for acquiring knowledge ; and to test at short intervals (say three to six months) the amount of progress he has made.

The scheme which I advocate, if fully developed, involves the appointment of suitable persons to act as tutors to the student in the several branches of study. Just as it is in the dissecting-room, where the value of the prosector's assistance is well recognised, so it would be in the museums of physiology, pathology, and materia medica. Under such a régime, any student who really wished to work would make sure progress, and would daily gain knowledge that would stay by him. Not a trifling advantage of this plan would be, I think, the doing away with all those abominable schedules, which are no small botheration both to student and teacher, and are almost useless, and sometimes, I fear; not over truthful, documents.

But I must now return from Utopia to hard reality. We have not got such a mode of education as I have sketched, and perhaps we never shall, unless the students themselves petition for it; so it only remains to do the best in our present case. The point where I think there is most room for improvement with many medical students is, that they are not enough in earnest about their work; they spend quite enough time over it, but they do not use that time to the best effect; they potter at their work instead of grappling it with hearty energy. I know that it may fairly be said that the student of medicine, unlike his fellows in other professions, cannot always find his work ready to his hand; that he cannot examine the relations of an artery, watch the effects of a drug, or study the symptoms of a disease, at the time when he wants to do so, and that, in consequence, his attention is apt to get distracted and languid. But, admitting that he has this difficulty to contend with, I fear it is quite undeniable that the opportunities, when they do come, are often not used as they should be. I wonder how many extremities in the dissectingroom are thoroughly worked through; the origins and insertions of every muscle clearly seen, and those of the large vessels and nerves carefully studied. What is the percentage of students who take notes in the wards and observe cases, so that they may abide with them as life-long lessons? I fear the shortcomings in these respects are too evident to admit of any doubt. Is the knowledge which the student gets, or imagines he gets, as he saunters round the wards, every now and then chatting with his neighbour, to be compared with that which he would obtain if he set himself to the careful study of cases with his note-book? Let us hear what Sir B. Brodie thought on this matter. He says, in his Autobiography: "My custom has been to take short notes at the bedside of the patients in the day, and to expand them with the aid of my memory in the evening. After an experience of nearly fifty years, I am satisfied that no one can be well acquainted with his profession, either as a physician or surgeon, who has not studied it in that manner. It is only by these means that a case can be thoroughly and scientifically investigated, or that that minute and accurate knowledge can be obtained of it which is necessary to a right diagnosis. I have always, during the many years in which I was a teacher and hospital surgeon, endeavoured to impress on the minds of my pupils the necessity of making and preserving such written records of their experience; and I have often been pained to observe how small a proportion have followed the advice I gave them. The great mass of students, whose period of professional education is limited, are so occupied by the great and (as I think) unnecessary number of lectures which they are now required to attend, and in running from one classroom to another, that they really have neither the leisure nor the physical powers necessary for pursuing in any efficient manner the practical study of disease in the wards of the hospital." Of the truth of the above remarks there cannot be two opinions; and, for my part, I think it is a cause for much regret, that clinical study is not much more diligently pursued in our out-patient rooms as well as in our wards. I agree entirely with the dictum of the great French therapeutist: "From the day when a young man selects medicine as his profession, he ought to frequent the hospitals. Il faut voir, toujours voir les malades."

But, turning from these regrets, let me bear the most glad testimony to the number of really excellent men whom St. Mary's School has produced. I may claim perhaps, beyond my colleagues, to speak strongly on this point; for most of those to whom I refer were educated at a time when $I$ was taking no active part in instruction, and, therefore, my testimony has the weight of that of an impartial observer. Of many of those who came under my notice as clinical assistants during the long years when I had 
charge of the out-patients, I can truly say that it was a real pleasure to associate with them; and that certainly as regards their work and their demeanour,
they were, like the chevalier of old, sans peur et sans reproche.

Follow, I pray you, their examples, and imbibe their spirit. The true temper of a student, as I take it, is a downright earnest resolve that he will accomplish the work before him, and a feeling akin to contempt for indolence and shirking. What, indeed, can be more contemptible, in a calling which concerns itself with the care of human life, than the neglect to obtain a competent knowledge of the means by which we are to be useful to others, and to avoid the stigma of being drones in the working hive. Truly, he who is guilty of such neglect will verify the old Greek saying, "The avenging deities have leaden feet, but iron hands." The retribution for wasted time and lost opportunities may come upon him slowly, but come it will; and, when it has him in its gripe, repentance is too late. I will not believe that any of you will ever earn for yourselves such sad regrets; but it may not be amiss if I press on your attention the assured truth, that one of the laws of the existing constitution of things is present sacrifice for future gain; and that this rules the several stages of this life in their relation to each other, as well as the whole of this life in relation to the next.

Lastly, I would say a word of advice as regards recreation. Do not think it out of place that I should advert to this matter. I an deeply persuaded of the importance of innocent cheerful relaxation for all of us, but especially for the young. I. believe it impossible that our brain-machinery can continue in full and energetic play, unless the nerve-power, which is consumed by mental effort, be restored by some of those délassemens which we will term recreaiions. This monition is often most needed by our best workers, who, from the highest motives, are apt to toil on too closely until their health becomes seriously impaired. I would impress on all of you that the goal of excellence in this or in any other calling is not so well-if at all-to be reached by fierce sudden spurts, as by well sustained nnflagging efforts, and these cannot be put forth by an enfeebled and suffering system. The men who have proved the best statesmen in India have often been keen sportsmen, who gained in tiger-hunting the nerve and resolve which subsequently stood them in good stead in serious political emergencies. I cannot doubt that the youth who trains his muscles and nerves to a skilful use of the bat, the oar, or the rifle, or practises any athletic exercise, will, if he be at the same time a conscientious worker, prove a better physician or surgeon than the one who has neglected to cultivate his bodily energies. The brain, which is dulled with incessant work, though it may be more replete with learning, is incapable of those quick keen intuitions which often lead to correct diagnosis, or suggest the right mode of treatment in difficult emergencies. Deal, however, honestly with yourselves, and take care that the relaxation you give yourselves is earned by downright honest work. Here comes in the worth of earnest activity in the economy of time ; it accomplishes so much more in an allotted period than halfhearted languid labours that space remains for recreation or other matters. Let me remind you of the reply made by a man of great attainments to a friend, who asked him how he had been able to accomplish so much. "Oh," said he, "I have no particular plan; when I have got anything to do I go and do it-that's all !' Contrast with this the confession once made to me by a man of great ability, that he always felt disposed to defer anything to the morrow which could by possibility be left undone that day!! I suspect this latter tendency is very much ingrained in human nature, and requires watching against in us all.

And now, in conclusion, let me observe that I set before you no unattainable aim-nothing that does not approve itself as reasonable and right to your own convictions. I invite you to no high soaring flights of earthly ambition. I have no mind to stimulate your energies with visions of great fame, wealth, and eminent position. These things may or may not come according to the appointment of the Ordainer of all things, but they are not very likely to be the lot of any of us, nor are they things to be passionately desired. The thirst for glory and distinction is, I know, no mean incentive to effort, but the sense of duty is a mightier. During the sternest part of the hard fought day at Waterloo, the Duke said to the soldiers of a square, "Stand fast, men, we must not be beaten; what would they say of us in England ?" The noble fellows replied, "Never fear us, sir, we know our duty." Here was no ambition, but the simple strength of moral principle in men of humble rank, and we know that that enduring energy carried the day. So I would have it with you. Few of us may be very distinguished here-all may win glory hereafter. What we may all do, and what I call on you to do, is to be workers in God's world, standing on the side of the brave, the good, the loving, the true, resolute to do your duty in fidelity to your baptismal vow, fellow-helpers with Christ and His angels. This is real manliness; this is worth living for. Gentlemen, be thus manly.

Miss GaRRETT, on Thursday, Sept. 28, passed her final examination, and received a licence from Apothecaries' Hall. She is about to deliver a course of lectures on Physiology exclusively to women at the Working Women's College, Queen Square.

Prostitution under Military Law. Two years ago, when General Rosecrans commanded the army of the Cumberland, syphilitic disease prevailed to such an extent as to disable hundreds of his soldiers. In the month of July, the General ordered all the abandoned women out of the state, and a whole cargo of unfortunates were shipped North. The boat touched at Louisville, but was ordered away by the authorities. It then attempted to land its freight at Cincinnati, but failed. It anchored in the river a few days, and soon after departed for Nashville, where it subsequently arrived and unloaded, costing the government several thousand dollars. But Rosecrans was not to be frustrated. His men were noi only being made unfit for service, but a great number of them had been absolutely ruined by their unlawful companionship with lewd women. As the terrible evil could not be annihilated, it was at once resolved to legalise and systematise the avocation of prostitution. Hospitals for the reception of diseased women were speedily built, examining physicians appointed, etc., etc. The result claimed for the experiment was, that in General Sherman's army of 100,000 men or more, but one or two cases were known to exist, while in Rosecrans' army of 50,000 men, there had been nearly 1500 cases. The women were examined once every ten days, paying two dollars for an examining fee, and five dollars a month to ply their avocation. The money was appropriated to hospital uses, and provision thus made for the sick of this class. The institution was nearly self-supporting, the entire expenditure of the hospital for ten months being 6,154 dollars, to meet which the fees collected from abandoned women amounted to 5,900. Such are the statements made by a correspondent of the New York Times, writing from Nashville. ('Miladelphia Medical Reporter.) 